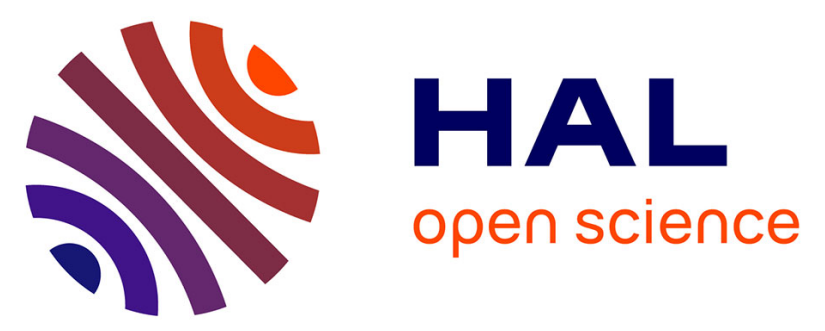

\title{
Successful Biodegradation of a Refractory Pharmaceutical Compound by an Indigenous Phenol-Tolerant Pseudomonas aeruginosa Strain
}

Sabra Hemidouche, Lidia Favier, Abdeltif Amrane, Patrick Dabert, Sophie Le Roux, Zahra Sadaoui

\section{To cite this version:}

Sabra Hemidouche, Lidia Favier, Abdeltif Amrane, Patrick Dabert, Sophie Le Roux, et al.. Successful Biodegradation of a Refractory Pharmaceutical Compound by an Indigenous Phenol-Tolerant Pseudomonas aeruginosa Strain. Water, Air, and Soil Pollution, 2018, 229 (3), pp.103. 10.1007/s11270018-3684-6 . hal-01771093

HAL Id: hal-01771093

https://hal-univ-rennes1.archives-ouvertes.fr/hal-01771093

Submitted on 27 Apr 2018

HAL is a multi-disciplinary open access archive for the deposit and dissemination of scientific research documents, whether they are published or not. The documents may come from teaching and research institutions in France or abroad, or from public or private research centers.
L'archive ouverte pluridisciplinaire HAL, est destinée au dépôt et à la diffusion de documents scientifiques de niveau recherche, publiés ou non, émanant des établissements d'enseignement et de recherche français ou étrangers, des laboratoires publics ou privés. 


\title{
Successful biodegradation of a refractory pharmaceutical compound by an indigenous phenol tolerant Pseudomonas aeruginosa strain
}

\author{
Sabra Hemidouche ${ }^{\mathrm{a}, \mathrm{b}}$,Lidia Favier ${ }^{\mathrm{c}}$, AbdeltifAmrane ${ }^{\mathrm{c}}$, Patrick Dabert ${ }^{\mathrm{d}}$, Sophie Le Roux ${ }^{\mathrm{d}}$, Zahra Sadaoui ${ }^{\mathrm{a}}$ \\ ${ }^{a}$ Laboratoire de Génie de la Réaction, Faculté de Génie Mécanique et de Génie des Procédés, Université des \\ Sciences et de la Technologie Houari - Boumediene,BP n³2 el Alia Bab -Ezzouar 16111, Alger, Algeria \\ ${ }^{b}$ Centre de Recherche Scientifique et Technique en Analyses Physico-Chimiques, BP 384, Siège ex-Pasna Zone \\ Industrielle, Bou-Ismail CP 42004, Tipaza, Algeria \\ ${ }^{c}$ Ecole Nationale Supérieure de Chimie de Rennes, CNRS, UMR 6226, 11Allée de Beaulieu, CS 50837, 35708 \\ Rennes Cedex 7, France \\ ${ }^{d}$ IRSTEA -UR Gestion Environnementale et traitement biologique des déchets(GERE), 17, avenue de Cucillé - \\ CS 64427, 35044 Rennes, Cedex, France

\section{*Correspondig Authors:}

Dr. Lidia Favier, Associate Professor

Ecole Nationale Supérieure de Chimie de Rennes, CNRS, UMR 6226, 11 Allée de Beaulieu CS 50837, 35708 Rennes Cedex 7, France.

Tel.: +33 233238135; Fax: +33 223238120

E-mail: lidia.favier@ensc-rennes.fr

\section{Prof. Abdeltif Amrane}

Ecole Nationale Supérieure de Chimie de Rennes, Université de Rennes 1, CNRS, UMR 6226, 11 Allée de Beaulieu CS 50837, 35708 Rennes Cedex 7, France.

Tél: +33 2232381 55; Fax: +33 223238120

E-mail: abdeltif.amrane@univ-rennes1.fr

Prof. Zahra Sadaoui

Laboratoire de Génie de la Réaction, Faculté de Génie Mécanique et de Génie des Procédés, Université des Sciences et de la Technologie Houari - Boumediene, BP n³2 el Alia Bab -Ezzouar 16111 Alger, Algérie E-mail: sadaouizahra@yahoo.fr

\section{Abstract}

This study provides an alternative solution for the bioremediation of a recalcitrant pharmaceutical micropollutant. Clofibric acid (CLA) was chosen as target molecule, because of its environmental persistence and resistance to wastewater treatment technologies. The aim of this study was to investigate the potential of a phenol resistant Pseudomonas aeruginosa strain isolated from the activated sludge to degrade CLA. In order to evaluate the effect of acclimation process with glucose as carbon co-substrate, two protocols were carried out, in which the transfer of the inoculum is carried out either in the exponential growth phase or in the decline phase. The results showed a removal efficiency of CLA of 35\% when cells in the decline phase were used for inoculation. In contrast, a very low removal yield (10\%) was achieved when cells harvested in the exponential phase were used as inoculum.

This work is the first one reporting on the capability of this bacterium to remove this drug. The obtained data showed that the isolated strain is able to degrade target molecule and might be a promising agent for the elimination of this refractory compound.

Keywords: pharmaceutically active compounds; clofibric acid; biodegradation; Pseudomonas aeruginosa RZS9, acclimation. 


\section{Introduction}

During the last decade, the occurrence of pharmaceutically active compounds (PhACs) into the aquatic environment have become an increasingly issue for environmental regulators and pharmaceutical industry (Cardoso et al. 2014; Favier et al. 2015; Zuccato et al. 2010). Several investigations have shown that substances of pharmaceutical origin are not efficiently removed during the wastewater treatment process, and also not biodegraded in the environment (Salgado et al. 2012; Semrany et al. 2012; Tauxe-Wuersch et al. 2005). Clofibric acid (CLA) is the main metabolite and the pharmacologically active component of the lipid regulators clofibrate, etofibrate, and etofyllinclofibrate (Cruz-Morató et al. 2013). These substances are used as antilipaemic agents (Kosjek et al. 2009). Their concentration levels in surface water and effluent from sewage treatment plants (STPs) have been shown to lie in the $\mathrm{ng}^{-1}$ to $\mu \mathrm{g} \mathrm{L}^{-1}$ range (Sacher et al. 2001; Salgado et al. 2010). Recent investigations report that CLA concentration in natural surface water at the highest levels approaches $240 \mathrm{ngL}^{-1}$ (Luo et al. 2014). The environmental concern related to CLA arises from its environmental persistence, with an estimated environmental residence time of 21 years (Doll et al. 2003; Khetan and Collins 2007). Several techniques have been investigated for the CLA removal including ozonation, photocatalysis, advanced oxidation processes and biological treatment (Nakada et al. 2007). Physicochemical methods lead to the best CLA degradation yields ( $>90 \%$ ), but the inherent drawbacks due to the tendency of the formation of secondary toxic by-products and the cost related to these kind of advanced technologies are significant and they pose maintenance problems (Jones et al. 2007), which make them economically unfeasible for many municipalities. Microbial degradation with specialized cultures is considered as an attractive alternative because of economic reasons and low possibility of hazardous byproducts formation (Sahinkaya and Dilek 2007). Up to now, only Zwiener and Frimmel (2003) have studied the biodegradation of three PhACs (clofibric acid, ibuprofen, and diclofenac) in a pilot sewage plant (PSP) and biofilm reactors (BFR) under aerobic and anaerobic conditions. The obtained results clearly showed that the both systems are inefficient for the elimination of clofibric acid and diclofenac under aerobic conditions with only approximately 5\% of degradation. More recently, Salgado et al. (2012) evaluated the elimination of CLA in an aerobic sequencing batch reactor (SBR) with mixed microbial cultures after acclimation over a period of 20 months. The maximum removal yield achieved was $51 \%$ for an initial CLA concentration of $2 \mathrm{mgL}^{-1}$. Furthermore, Evangelista et al. (2010) studied the biodegradation of three chlorophenoxy acids using axenic cultures of bacteria under cometabolic conditions. Nevertheless, none of the tested microorganisms was able to degrade clofibric acid suggesting that the recalcitrance of clofibric acid is due to the additional methyl group adjacent to the ether bond (2010).

Some studies reported that cultures acclimated to a specific type of xenobiotics compounds such as chlorophenols with an aromatic ring have also the ability to degrade other compounds with similar structure (Murcia et al. 2012; Sahinkaya and Dilek 2007).

However, literature data on the biodegradation of CLA with short-term experiments by pure cultures of bacteria belonging to the genus of Pseudomonas remains very scarce.

In this framework, the present study evaluates the ability of a phenol resistant Pseudomonas aeruginosa strain to remove CLA in liquid system. For this purpose, an acclimation study of the strain to the micropollutant was carried out in the presence of carbon co-substrate (D-glucose). The effect of glucose concentration on the CLA biodegradation was also examined. 


\section{Materials and methods}

\subsection{Microorganisms}

The strain Pseudomonas aeruginosa, used in this work was isolated from an activated sludge collected in the aeration tank of the Municipal Sewage Treatment Plant of Beni Messous (Algeria). $500 \mathrm{~mL}$ of sludge was introduced in an Erlenmeyer flask and was aerated for a period of 24h. The aeration process was then stopped for $30 \mathrm{~min}$ in order to separate the sludge from the liquid phase. $250 \mathrm{~mL}$ of the supernatant was replaced by a solution volume of phenol in order to have a final concentration of $500 \mathrm{mgL}^{-1}$ and then aeration was started again. After $24 \mathrm{~h}$ of incubation time, $89 \%$ of phenol biodegradation was noted. Appropriate serial dilutions of resistant strain suspension were then prepared with $\mathrm{NaCl}(0.9 \%, \mathrm{w} / \mathrm{w})$ before plating onto nutrient agar (NA) and incubated for $24 \mathrm{~h}$ at $37^{\circ} \mathrm{C}$. Colonies showing good growth were selected and transferred into a fresh nutrient agar. This procedure was repeated three times in order to ensure the cultures purity. The stock culture was stored at $-20^{\circ} \mathrm{C}$ in $80 \%$ glycerol.

\subsection{Chemicals and growth media}

CLA (>99\% of purity) was purchased from Acros Organics (New Jersey, USA). Table 1shows the physicochemical characteristics of the target compound. The solvents of HPLC-grade, acetonitrile, formic acid (99.9\%) were provided by Fisher Scientific (Geel, Belgium) and D-glucose anhydrous was bought from Merck (Darmstadt, Germany).

\section{Table 1}

Mili-Q ultrapure (resistivity of $18 \mathrm{M} \Omega \mathrm{cm}$ at $25{ }^{\circ} \mathrm{C}$ ) obtained from a Milipore system was used for the preparation of all aqueous solutions. All other chemicals and nutrient media were purchased from Acros Organics (New Jersey, USA). For the batch degradation experiments and acclimation studies, a stock solution of CLA was prepared at $50 \mathrm{mgL}^{-1}$ in ultrapure water and stored at $4^{\circ} \mathrm{C}$ until use.

Inoculum preparation was carried out in nutrient broth medium (N.B.) in order to promote increased biomass growth. The used medium contained: $10 \mathrm{gL}^{-1}$ tryptone, $5 \mathrm{gL}^{-1}$ meat extract and $5 \mathrm{gL}^{-1}$ sodium chloride. $5 \mathrm{~g}$ of the N.B. powder were weighed and slowly dissolved by magnetic stirring until complete dissolution in $250 \mathrm{~mL}$ of ultrapure water into an Erlenmeyer flask of $500 \mathrm{~mL}$. The flask was then covered by a cotton cap and aluminum foil and autoclaved at $121^{\circ} \mathrm{C}$ for 15 minutes.

For the biodegradation and acclimation experiments a basal mineral medium (BMM) was employed. It contains the following compounds with concentrations expressed in $\left(\mathrm{gL}^{-1}\right)$ : $\mathrm{K}_{2} \mathrm{HPO}_{4}, 4.25 ; \mathrm{KH}_{2} \mathrm{PO}_{4}, 1.70 ; \mathrm{NH}_{4} \mathrm{Cl}, 2.10$; $\mathrm{MgSO}_{4} \cdot 7 \mathrm{H}_{2} \mathrm{O}, 0.41 ; \mathrm{MnSO}_{4} \cdot \mathrm{H}_{2} \mathrm{O}, 0.06 ; \mathrm{FeSO}_{4} \cdot 7 \mathrm{H}_{2} \mathrm{O}, 0.01 ; \mathrm{CaCl}_{2} \cdot 2 \mathrm{H}_{2} \mathrm{O}, 0.03$. The medium $\mathrm{pH}$ was adjusted to 7.3 with $\mathrm{NaOH}(2.5 \mathrm{M})$ prior to sterilization. Finally, CLA was added in the BMM and then autoclaved at $121^{\circ} \mathrm{C}$ for 20 min, as it was determined that the target molecule is not heat labile.

The carbon co-substrate (D-glucose) was dissolved in ultrapure water and was sterilized separately to avoid Maillard reactions and hence a color change of the medium during the autoclaving process, and then added aseptically to the sterilized medium to yield the appropriate final concentration according to the requirements for the biodegradation tests or acclimation procedure. 


\subsection{Growth experiments}

\subsubsection{Preparation of the inoculum}

Between experiments, the bacterial isolate was preserved by nutrient agar plating at $4^{\circ} \mathrm{C}$ and then subcultured. Before each experiment, the strain was cultured for $48 \mathrm{~h}$ in nutrient broth (Biokar Diagnostics, Beauvais) at 150 rpm and at $37^{\circ} \mathrm{C}$. The obtained culture suspension was then centrifuged at $5000 \mathrm{rpm}$ for 10 min (Jouan C412, Saint-Herblain, France), washed twice with sterile ultrapure water in order to remove organic substances adsorbed on biomass and was finally re-suspended in the same volume in minimal basal media (BMM). The concentration of the final cell suspension was adjusted to a suitable optical density (1.2) at $600 \mathrm{~nm}$. This procedure was repeated each time for inoculum preparation.

\subsubsection{Biodegradation and biosorption experiments}

All biodegradation tests were performed in duplicate and were conducted in batch mode. For this purpose Erlenmeyer flasks with a volume of one liter stoppered with cotton plugs were employed. For the assays with CLA as the sole carbon source the drug was added in $250 \mathrm{~mL}$ of basal minimal medium in appropriate proportions to give the desired pollutant concentration and then sterilized. Different initial concentrations of CLA were examined (ranging from 0.25 to $\left.2 \mathrm{mgL}^{-1}\right)$. For each experiment, $10 \mathrm{~mL}$ of inoculum $\left(\mathrm{OD}_{600}=1.2\right)$ was added. The flasks were maintained at $37^{\circ} \mathrm{C}, \mathrm{pH}=7 \pm 0.1$ and at constant stirring rate (150 rpm). Furthermore, two controls were done in parallel with CLA without microorganism and with biomass without drug in order to study the bacterial growth in the absence of the target molecule and the possible abiotic degradation of CLA. In order to investigate the effect of glucose on the degradation of CLA, Pseudomonas aeruginosa cells were grown in basal mineral medium with $2 \mathrm{gL}^{-1}$ of glucose and $1 \mathrm{mgL}^{-1}$ of CLA. This test was carried out under the same conditions as the biodegradation test with CLA and without co-substrate.

In addition, biosorption experiments were carried out under similar conditions to those described for biodegradation tests in order to evaluate the significance of the adsorption process by the bacterial biomass on the total removal of the target molecule. They were performed with inactivated cells (autoclaved $121^{\circ} \mathrm{C}$ for 20 min). The samples were collected from the flask at several time intervals $(0.5,1,1.5,2$, and $24 \mathrm{~h})$ and the CLA content in the supernatant was analyzed by HPLC-UV.

The presence of CLA adsorbed onto the biomass was also highlighted by the use of the modified method of ultrasonic solvent extraction described by Salgado et al. (2012). For this method, samples were taken at the end of the biodegradation experiments (168 h) and centrifuged as described before (section 2.3.1). Briefly, 2 x $4 \mathrm{~mL}$ of acetonitrile was added to the centrifuged biomass sample, which was subjected to sonication treatment to suspend the biomass. The CLA extraction process was performed in an ice bath with four bursts of $30 \mathrm{~s}$ (amplitude 20\%) with 59 s intervals using a Vibra Cell sonifier (Bioblock Scientific, Illkirch, France). After sonication the samples were centrifuged again at $5000 \mathrm{rpm}$ for $10 \mathrm{~min}$. The obtained supernatants were filtered using $0.2 \mu \mathrm{m}$ pore size syringe filters in HPLC vials and then were analyzed in HPLC-UV. 


\subsubsection{Acclimation process}

In order to obtain acclimated cultures, two different protocols were tested in this work. They were performed by consecutive batch assays (multiple transfer or enrichment) in the presence of carbon co-substrate. In order to select the most efficient acclimation strategy, the degradation of CLA by Pseudomonas aeruginosa was investigated.

Protocol I: The cultures were acclimated to CLA by sequential transfers, in a series of shake flasks (1L), decreasing glucose concentrations from 2 to $0.25 \mathrm{gL}^{-1}$, and gradually increasing CLA concentrations from 0.25 to $2 \mathrm{mgL}^{-1}$, over a period of one week. Every 24h (end of exponential phase), bacterial biomass was harvested by centrifugation (5000 rpm for $10 \mathrm{~min}$ ) and washed twice with ultrapure water. The pellet was then re-suspended in fresh BMM medium. $10 \mathrm{~mL}$ of cells suspension were used to inoculate in a new flask containing fresh BMM medium (different concentrations of glucose and CLA).

Protocol II: Similar to Protocol I, but the acclimation period was longer (one month). All cultures were regularly transferred at intervals of $72 \mathrm{~h}$ (decline phase) to fresh medium, under the same conditions as protocol I. It should be noted that the both strategies were conducted at a fix reaction time (cycle duration $24 \mathrm{~h}$ or $72 \mathrm{~h}$ ) in order to use different quality of inoculum and as a consequence to evaluate the effect of this parameter for the acclimation. Moreover, the both procedures are independent of the degree of pollutant removal. For each assay, samples were taken at different times to determine the residual CLA concentration and the optical density. The acclimation process was monitored by calculating the CLA removal yield.

\subsection{Analytical methods}

Samples were aseptically taken at regular intervals and investigated for cell density, medium pH, CLA removal and glucose consumption. $4 \mathrm{~mL}$ of sample from each flask was taken for the determination of all cited parameters. Medium pH was measured using a small pH electrode (CyberScan, Thermo Scientific, France) suitable for small volume samples. Cell growth was monitored by measuring the absorbance at $600 \mathrm{~nm}$ using UV-Vis single beam spectrophotometer (ThermospectronicHe $\lambda$ ios, Cambridge, UK).

To prevent the fouling of the chromatographic column, the samples require, before injection, a very simple pretreatment based on deproteinization. This treatment was performed with $\mathrm{Ba}(\mathrm{OH})_{2}$ and $\mathrm{ZnSO}_{4} 7 \mathrm{H}_{2} \mathrm{O}$. Both compounds cause the precipitation of proteins present in the samples. $2 \mathrm{~mL}$ of sample was treated by addition of $0.25 \mathrm{~mL}$ of $\mathrm{Ba}(\mathrm{OH})_{2}(0.3 \mathrm{M})$ and $0.25 \mathrm{~mL} \mathrm{ZnSO}_{4} \cdot 7 \mathrm{H}_{2} \mathrm{O}(5 \% \mathrm{w} / \mathrm{w})$. The supernatant obtained after $10 \mathrm{~min}$ of centrifugation at $5000 \mathrm{rpm}$ was filtered through a membrane filter of Polyester (Chromfil ${ }^{\circledR}$ Xtra, MachereyNagel, Germany, porosity $0.2 \mu \mathrm{m}$ ) and used for CLA and glucose analysis.

The residual CLA concentration was determined using a Waters 2695 Alliance HPLC system equipped with a UV-detector (Waters2489 dual $\lambda$ absorbance detector) operating at a wavelength of $230 \mathrm{~nm}$. Chromatographic separation was achieved on a C18 column ( $250 \times 4.6 \mathrm{~mm}, 5 \mu \mathrm{m}$, Waters, Ireland) and at $30^{\circ} \mathrm{C}$. The mobile phase consisted of a mixture of acetonitrile-ultrapure water $(40: 60, \mathrm{v} / \mathrm{v})$ and $0.1 \%$ formic acid at a flow rate of $1.0 \mathrm{~mL}$ $\min ^{-1}$. The injection volume was $50 \mu \mathrm{L}$. The retention time of CLA under these analytical conditions was 12.54 min and the instrumental quantification limit (LOQ) for this drug was $<150 \mu \mathrm{gL}^{-1}$. The chromatogram of a standard CLA solution is shown in Fig.1. 
Glucose consumption during the biodegradation experiments was verified by ion chromatography using the Dionex DX 600 system (Dionex Corporation, Sunnyvale, Canada) equipped with a pulsed amperometric detector with a gold working electrode, a GP50 gradient pump, and an AS40 automated sampler (Dionex Corporation, Sunnyvale, CA). A guard column $(4 \times 50 \mathrm{~mm})$ was placed in-line prior to the analytical column in order to protect it for fouling. Analyte separation was achieved with a CarboPac PA1 Analytical (4x250 mm) column. The column was eluted by a mixture of ultrapure water - $\mathrm{NaOH}(200 \mathrm{mM})\left(90: 10\right.$, v/v) at a flow rate of $1.0 \mathrm{~mL} \mathrm{~min}^{-}$

${ }^{1}$.The volume of the injected sample was $20 \mu \mathrm{L}$. Under these analytical conditions the retention time of glucose was 7.81 min. Data acquisition was achieved with Chromeleon software, v.6.80 (Dionex Corporation, Sunnyvale, CA).

All measurements were carried out in duplicate and mean values were used for the data analysis and calculations.

\section{Results and discussion}

\subsection{Strain identification}

For preliminary identification at species level, bacterial isolate was examined by using standard biochemical and morphological tests (macroscopic and microscopic) provided in the Bergey’s Manual of Determinative Bacteriology (Holt et al. 1994). For macroscopic evaluation nutrient agar from Biokar diagnostics, containing (g $\mathrm{L}^{-1}$ ): tryptone, 10; meat extract, 5; NaCl, 5; bacteriological agar, 15; $\mathrm{pH}$ 7.1, was used as a basal medium to study the morphological characteristics of pure culture. Bacterial colonies in this medium were circular with a diameter 1-3mm, with fluorescent yellow green color, smooth shape and mucous consistency. Moreover, the obtained bacterial colonies could be easily scraped off from the solid agar media incubated at $37^{\circ} \mathrm{C}$. Biochemical tests and microscopic evaluation revealed that, the bacterial isolate is Gram negative, motile by polar flagella, positive for oxidase, catalase, citrate, arginine dihydrolase (ADH) and glucose in MEVAG medium (medium for the study of the carbohydrates attack way) through oxidative way. However, they are negative for indole, methyl red and Voges proskauer tests (glucose fermentation ability). Indeed, the selected strain is not able to use glucose under anaerobic condition. The results of strain identification are detailed in Table 2.

According to Holt et al. (1994) all these morphological and biochemical characteristics allow us to identify the studied strain as a species of the Pseudomonas genus. In order to complete the identification of the bacterial isolate, 16S RNA gene of pure bacterial culture was amplified and sequenced. As previously reported, such approach is considered as a valuable technique in taxonomic analysis of bacteria. DNA was extracted using NucleoSpin®Microbial DNA kit. The 16S rDNA gene was amplified by PCR using forward and reverse primers 9F (5'-GAGTTTGATCMTGGCTCAG-3') (Gordon et al. 1997) and 1509R (5'- GNTACCTTGTTACGACTT-3') (Weisburg et al. 1991), based on the Escherichia coli 
$\mu \mathrm{L}^{-1}$ ), $2.5 \mu \mathrm{L}$ of $10 \times$ PCR buffer, $2 \mu \mathrm{L}$ of dNTP (2.5 mM each), $1.5 \mu \mathrm{L}$ of forward primer (10 $\left.\mu \mathrm{M}\right)$ and $1.5 \mu \mathrm{L}$ of reverse primer $(10 \mu \mathrm{M}), 0.75 \mu \mathrm{L}$ of $\mathrm{MgCl}_{2}(50 \mathrm{mM}), 1 \mu \mathrm{L}$ of DNA template and sterile water to $25 \mu \mathrm{L}$ reaction volume.PCR amplification was carried out under the following conditions: initial denaturation at $94^{\circ} \mathrm{C}$ for 2 min, followed by 25 cycles at $94^{\circ} \mathrm{C}$ for $1 \mathrm{~min}, 50^{\circ} \mathrm{C}$ for $1 \mathrm{~min}$, and $72^{\circ} \mathrm{C}$ for $1 \mathrm{~min}$, with a final extension at $72^{\circ} \mathrm{C}$ for $10 \mathrm{~min}$. DNA sequencing of the PCR fragments was carried out by the Biogen Ouest facility (Nantes, France). Obtained 16SrRNA gene sequence was compared to GenBank entries and identified via BLAST algorithm. The analysis showed that the 16S rRNA of the isolated strain shared100\% similarity with the 16S rRNA gene of the Pseudomonas aeruginosa strain RZS9, deposited in GenBank with the accession number KP866815.

\subsection{Biodegradation studies of CLA without strain acclimation}

\subsubsection{Study without co-substrate}

In order to evaluate the capacity of bacterial isolate to grow in the presence of CLA as sole carbon and energy source, series of growth experiments were conducted in BMM medium at different CLA concentrations (ranging from 0.25 to $2 \mathrm{mgL}^{-1}$ ).Time-course variations in biomass (expressed as optical density), $\mathrm{pH}$ and CLA residual concentration were followed for the unacclimated cultures. The corresponding results are given in Fig.2 (a, b, c).It was seen from the results that similar growth profiles are obtained for all individual experiments and the rise of the initial concentration of CLA from 0.25 to $2 \mathrm{mgL}^{-1}$ led to only a slow decrease of the bacterial growth $\left(\mathrm{OD}_{600}=0.5\right.$ to 0.3$)$ (Fig.2a). No lag phase was observed at the beginning of the strain growth. Pseudomonas aeruginosa RZS9 directly entered in growth phase from an incubation time between 0 and $72 \mathrm{~h}$ while, from $72 \mathrm{~h}$ to $264 \mathrm{~h}$ an important decrease in the cell growth was observed. The absence of the lag phase in the bacterial growth can be due to the low pollutant concentrations used in this work. This observation agrees with the study of Murcia et al. (2012) with Pseudomonas putida where no lag time was achieved with the low concentrations in 4-chlorophenol, whereas bacterial required a lag phase of $40 \mathrm{~h}$ before exhibiting the growth at a pollutant concentration of $200 \mathrm{mgL}^{-1}$ and more than $70 \mathrm{~h}$ at $250 \mathrm{mg} \mathrm{L}^{-1}$.

Moreover, Fig 2a shows that bacterial cells survived in the presence of the pollutant. However, the maximum cell density achieved at the end of the growth phase remains quite low (up to $0.5 \mathrm{OD}_{600}$ units). The time required to reach the maximum biomass concentration was similar (72h) for all the tested conditions. These observations are in agreement with those reported previously by Larcher and Yargeau (Larcher and Yargeau (2011) for Pseudomonas aeruginosa (PA01) and Pseudomonas putida (123633) exposed to sulfametoxazole as the sole carbon source.

In addition, it should be noted that a control experiment without pollutant was also conducted (as previously reported in section 2.3.3) and the growth profile was quite identical to the one of the experiment done at initial CLA concentration of $0.25 \mathrm{mgL}^{-1}$. Based on the successful cells growth in the presence of drug it was expected to observe a pollutant removal user the considered experimental conditions. However, no degradation of the target molecule was observed with unacclimated biomass during 264h of incubation time at any of the tested initial pollutant concentrations (Fig.2b). These results were in agreement with those reported for clofibric acid and carbamazepine when exposed to cultures of Streptomyces spp (Popa et al. 2014; Popa et al. 2016). Larcher 
and Yargeau (2011) observed a very low removal yield (0-6.6\%) for sulfamethoxazole degradation experiments with individual bacterial species. Moreover, Gauthier et al. (2010) found that Rhodococcus rhodochrous and Aspergillus niger are not able to degrade carbamazepine and sulfamethoxazole when these molecules are the sole carbon sources.

The results obtained in our work confirmed that the isolated strain is unable to degrade the target molecule at all the investigated concentrations in monosubtrate system and the recalcitrance of CLA. Similar observations were reported by Evangelista et al. (2010). It can also be noted that no volatile loss of CLA was observed during the abiotic test (without microorganisms) (result not shown).

Fig. 2(a), (b), (c)

In addition, the $\mathrm{pH}$ of the medium remained almost constant during the biodegradation tests. This result indicates the absence of degradation metabolites usually formed during biodegradation processes which cause $\mathrm{pH}$ modification of the culture medium. Moreover, it confirms the data obtained on the removal of the target molecule.

The obtained results showed that during the degradation experiments, Pseudomonas aeruginosa RZS9 cells survive in the presence of pollutant but, no pollutant removal was detected in the presence of the target molecule. This suggests that CLA may not be used as the sole carbon or energy source to maintain the cells growth and to induce the enzymes needed for its assimilation. The bacterial growth observed under the investigated culture conditions could be probably attributed to the use of the carbon stored intracellularly during the preculture period conducted in nutrient broth allowing the cells maintenance and bacterial growth during the first $72 \mathrm{~h}$ of cultivation.

To overcome the toxic effect of the pollutant, especially at high pollutant concentration more energy is required. In this context, the presence of a growth substrate or another utilizable compound is obligatory required to maintain the biomass growth and to induce the corresponding enzymes and/or necessary for biodegradation. This process is well-known as co-metabolism (Tran et al. 2013). Therefore, it is of great interest to investigate if the addition of a carbon co-substrate reduce the toxicity of the target organic compound and enhance bacterial growth and the removal process.

\subsubsection{Study with co- substrate}

It was reported that in mono-substrate system, clofibric acid was resistant to microbial degradation [18]. As previously stated, different studies proved that microorganisms are able to degrade xenobiotics only under cometabolic conditions (Domaradzka et al. 2015; Fisher et al. 2010; Gauthier et al. 2010). Indeed, the addition of a co-substrate, which is a readily available source of carbon and energy, increases biomass production. Moreover, the presence of the growth substrate may also induce enzymes of xenobiotic decomposition pathways and in this way increases its degradation rate (Quintana et al. 2005; Grenni et al. 2013). For example, Fakhruddin and Quilty (2005) showed that the degradation of 2-chlorophenol was enhanced in the presence of glucose (up to 1\%). Similar results have been found for the degradation of another recalcitrant molecule, benzo[a]pyrene, by 
Pseudomonas saccharophilia and Stenotrophomonas maltophilia (Chen and Aitken 1999; Juhasz and Naidu 2000).

So for that reason, the effect of the addition of a growth substrate on the Pseudomonas aeruginosa RZS9 growth and CLA removal was investigated in this work. Study was carried out using glucose, as carbon co-substrate. To investigate its effect, an additional batch experiment test with $1 \mathrm{mgL}^{-1}$ of CLA in BMM supplemented with $2 \mathrm{gL}^{-}$ ${ }^{1}$ of glucose was carried out. The operating conditions of this test were the same to those used for the biodegradation experiments without co-substrate. The corresponding results are given in Fig.3 (a, b).

Fig. 3 (a), (b)

These figures clearly illustrate the significant effect of the addition of glucose on bacterial growth, pH and CLA removal. Indeed, the carbon co-substrate addition led to an absence of the lag phase and to an increase in the optical density. The measured value is higher than the one determined in the presence of CLA as sole source of carbon and energy. Fakhruddin and Quilty (2005) have attributed this effect to the production of large quantities of cofactors such as NADH and NADPH resulting with oxidation of sugars.

The maximum growth $\left(\mathrm{OD}_{600}\right.$ up to 1.3) was reached after 24 hours of culture(Fig.3a) with practically total consumption of glucose (Fig.3b) while, in the absence of glucose $72 \mathrm{~h}$ were needed (Fig.3a). This value is more than the double that the one achieved with CLA as the sole source of carbon suggesting that glucose stimulate the bacterial cells growth. Regarding the measured $\mathrm{pH}$, it was observed that, during this period the $\mathrm{pH}$ of the culture medium decrease to 6.61. According to Loh and Wang (1997) and Salgado et al. (2012), this can be attributed to the formation of glucose degradation metabolites (acetic acid and lactic acid) leading to the acidification of the culture medium. As shown in Fig.3b, CLA removal reached almost 20\% after $72 \mathrm{~h}$ of incubation, and remained constant beyond this time. It is noteworthy that CLA removal occurred simultaneously with glucose consumption during this time and was accompanied by an increase in biomass. Moreover, the increase of pollutant removal observed in the presence of glucose can be due to an increased production of cofactors such as NADPH which could be the required cofactors for the key enzymes involved in the CLA metabolism.

It should be pointed out that, in separate sets of tests, abiotic elimination of pollutant (using the same conditions but without biomass) as well as, the adsorption of CLA to the biomass (data not shown) were investigated. Moreover, as previously stated (section 2.3.3), to check for possible adsorption of CLA onto the biomass at the end of the experiment, a supplementary adsorption test was performed at the end of the culture, 168h (data not shown). The obtained results suggest that, there is no evidence for abiotic degradation as well as for adsorption of drug to the cells surface (biosorption) confirming that the CLA removal observed in Fig. 3b was only attributed to the biodegradation process. This result was also confirmed by chromatograms obtained by HPLCUV analysis (data not shown) and is consistent to literature data. Indeed, several studies reported that the CLA sorption to sludge, suspended matter and sediments is not considered to be an important contribution to the elimination of this molecule from waste and surface waters (Kent et al. 2006; Kosjek et al. 2009). Moreover, in their work, Kosjek et al. (2009) excluded the possibility of abiotic degradation of CLA.

The addition of a more readily available carbon sources exerted a stimulatory effect on the cellular activity and as consequence, on the cells growth and the removal yield of CLA. Similarly to our study, Tran et al. (Tran et al. 
2009) found that the presence of acetate $\left(100 \mathrm{mgL}^{-1}\right)$ as an additional carbon source increases the CLA removal. In their previous work, Fakhruddin and Quilty (2005) observed the degradation of 2-chlorophenol by Pseudomonas putida CP1 in the culture media supplemented with glucose. Likewise, Strepromyces bacteria isolated from soils cometabolise CLA and carbamazepine in the presence of glucose as additional source of carbon and energy (Popa et al. 2014, 2015 and 2016).

Moreover, our results clearly showed that, the CLA removal proceed until a certain value and then did not continue. One explanation is that, the pollutant elimination is not limited by the glucose consumption because it continues after its depletion from the culture medium but, by an unknown nutrient (oxygen or another) present in the culture media or by the accumulation of an inhibitory metabolite which affects the CLA degradation. Similar results have been previously reported by Salgado et al. (2012) for the same molecule.

The obtained data show that Pseudomonas aeruginosa RZS9 is able to remove the target molecule in the presence of glucose. However, the CLA removal yield obtained with unacclimated culture still remains low confirming the high resistance to microbial attack of this molecule and suggests that adaptation of the strain to pollutant may be required to have a significant elimination of the target molecule. Several studies have reported that the capacity of bacteria to remove toxic compounds can be enhanced by acclimation (Evangelista et al. 2010; Ferro Orozco et al. 2013; Sahinkaya and Dilek 2005). Acclimation is considered as the key issue to achieve the degradation of recalcitrant compounds. Indeed, microorganisms which are repeatedly exposed to a pollutant may develop new capabilities to degrade toxic molecules. Thus in this study, the impact of the acclimation on the removal of the target molecule was also investigated.

\subsection{Investigation of acclimation strategy of Pseudomonas aeruginosa RZS9 to CLA}

Acclimation of an indigenous microbial species or population is essential to increase the potential of the elimination yield of an organic pollutant. Some studies indicated that the degradation of a persistent xenobiotic compound can be achieved only after going through an acclimation process (Chong 2009; Huang et al. 2014; Mangat and Elefsiniotis 1999). Indeed, during the acclimation process the microbial population can acquire new metabolic pathways for xenobiotic degradation (Chong and Lin 2007). In aerobic microbial communities the acclimation periods generally range from some hours to several days while for anaerobic communities this period is typically more longer (from two weeks to six months or longer) (Ye and Shen 2004). Other works pointed out that, this process depends on type and concentration of the xenobiotic compound, the type of considered microorganisms, the type of culture (pure or mixed), the presence of readily biodegradable compounds (Chong et al. 2008; Ye and Shen 2004), the level of inoculation and the physiological state of the inoculated cells, as well as the strategy under which acclimation was performed. Moreover, it has been mentioned that the degree of adaptation of a microorganism or a mixed culture varies depending on the used acclimation procedure.

In order to examine the impact of the acclimation process in the presence of a primary carbon source (glucose) two acclimation strategies were performed as described in the section 2.3.2. As stated before, the acclimation strategy used here was based on enrichment or multiple transfer approach by using inoculum of different qualities. Another possibility is to conduct this procedure in a single flask. CLA removal and optical density 
were monitored periodically for evaluation acclimation efficiency purposes. The removal yields of CLA at the end of the exponential phase $(24 \mathrm{~h})$ during acclimation are displayed in Fig. 4 for both investigated protocols.

Fig. 4

It can be observed that after acclimation in the presence of glucose as a primary carbon substrate the bacterial strain acquired the capability to degrade CLA. Moreover, the increase in the pollutant concentration had an impact on the level of degradation. Indeed, for both acclimation strategies the removal efficiency of Pseudomonas aeruginosa RZS9 increased with the initial pollutant concentration up to a threshold value ( $1 \mathrm{mgL}^{-1}$ of CLA and $1.25 \mathrm{gL}^{-1}$ of glucose). In the Protocol I, namely cells harvested in the exponential phase, after 24h of incubation, only $10 \%$ of CLA was degraded. However, in the same conditions, 35\% of CLA biodegradation was observed following the Protocol II, namely cells harvested in the decline phase, after 72h of incubation. These results suggested that, Protocol II appeared more efficient to the increase in pollutant concentration and its degradation than Protocol I. Protocol II is therefore more sensitive to the increase in pollutant concentration than the Protocol I. In fact, for the Protocol II, each step of the acclimation phase lasted 72h and hence, the existing glucose in the medium would be totally consumed at this stage of bacterial growth and consequently, only CLA remained in the acclimation medium; the cells would be therefore, better-adapted and more capable for pollutant degradation comparatively to the Protocol I. In other words, the adaptive pressure in the Protocol II was higher than during the Protocol I which leads to a lower degradation efficiency.

Pinto et al. (Pinto et al. 2012) reported a similar behavior for P. brevicompactum isolated from contaminated soil for the removal of difenoconazole. Awasthi et al. (Awasthi et al. 2009) also found that consortium adapted to mixed 2-ABTS/glucose substrates demonstrated rapid glucose removal with concomitant degradation of 2aminobenzenesulfonate.

Beyond the optimal concentrations ( $1 \mathrm{mgL}^{-1}$ of CLA and $1.25 \mathrm{gL}^{-1}$ of glucose), the removal yield decreased with the increase of initial CLA concentrations for the both considered protocols. This result could be attributed to the inhibitory and toxic effects caused by high pollutant concentrations (Fig.4). Similarly, Yamanaka et al. (2007) reported a toxic effect caused by high bisphenol A (BPA) concentrations. They found that in the range of 2-25 mg L $\mathrm{L}^{-1}$ BPA was effectively degraded by Bacillus pumilus but higher pollutant concentrations caused the inhibition of the degrading activity of the acclimated cells. Moreover, Zhang et al. (2007) reported that the degrading activity of Achromobacter xylosoxidans was affected by increased levels of toxicity for BPA.

Figure 5a depicts the biomass concentration profiles during the acclimation Procedure II for the batch test operated at $1 \mathrm{mgL}^{-1}$ of CLA and at $1.25 \mathrm{gL}^{-1}$ of glucose for an incubation time of $72 \mathrm{~h}$. It was observed that the $\mathrm{OD}_{600}$ value increased up to 1.0 during the first $24 \mathrm{~h}$ of incubation after that, a marked decreased of this parameter (up to 0.30 ) was reached after $72 \mathrm{~h}$ of culture reflecting the consumption of the more available carbon source (glucose) by the bacterial strain. Moreover, a concomitant decrease of the $\mathrm{pH}$ was observed during the first 24h of culture, probably due to the formation of biodegradation metabolites and then, the measured $\mathrm{pH}$ values remained without significant changes until the end of the batch assay (Fig.5b).

Fig.5 (a), (b) 
In addition, during this incubation time, a progressive augmentation of CLA removal yield can be observed until reaching a value of $46 \%$ after $72 \mathrm{~h}$ of incubation (Fig.5b). This value is higher than the one obtained under the same conditions but with unacclimated biomass, suggesting the positive role of the used acclimation strategy for the removal of this refractory pharmaceutic molecule. However, the complete removal of CLA was not obtained. It can be also observed that the removal of the target molecule continues also after the complete depletion of glucose from the culture media. As the culture time proceeds and with the presence of the target molecule, the acclimated biomass acquired new degradation capabilities due to a biochemical adjustment at intracellular level. While the degradation of an ordinary substrate is generally reflected by the microorganism growth, the degradation of a toxic molecule involves a capability factor within the biomass which has not always reflected in biomass growth. Only when a capability is gained, the utilization of the xenobiotic compound as substrate started, resulting in the growth of the adapted microorganism (Chong and Lin 2007). Thus, our results proved that during the acclimation process the Pseudomonas aeruginosa RZS9 biomass acquired new biodegradation abilities and can promote the pollutant removal even if the carbon co-substrate was completely consumed and the total biomass started to decrease. Indeed, under these conditions it is supposed that the resting active biomass can continue the degradation process. At this culture time, two types of cells are present in the culture media: the active acclimated biomass (degraders) which acquired the capability to degrade the CLA during the acclimation process and can use the pollutant as sole source of carbon and the non-degraders of the xenobiotic compound due to the cells death during the endogenous decay process. A pure evaluation of the active biomass and the calculation of the acclimation effectiveness in relation with this parameter can lead to a better understanding of the acclimation phenomenon considered in this work. Similar phenomena were reported previously by Chong and Lin (2007), when a mixed culture (such as activated sludge) was exposed to a xenobiotic compound (e.g. BPA).

To the best of our knowledge, the results obtained in our work with acclimated biomass are very promising because the achieved CLA removal efficiency was higher than those reported previously. Evangelista et al.[18] found for Rhodococcus rhodochrous an elimination yield of 90\% for a solution of CLA of $100 \mathrm{mgL}^{-1}$ but after a long acclimation period of 20 days. Winkler et al. (2001) reported that CLA was not removed at an initial concentration of $90 \mu \mathrm{gL}^{-1}$ over a time period of $400 \mathrm{~h}$ and only $27 \%$ of elimination was achieved in a biofilm reactor feed with river water spiked at $11 \mu \mathrm{gL}^{-1}$ after a culture time of 95h. In another work, Tran et al. (2009) obtained a maximum elimination yield of $25 \%$ with enriched nitrifier culture for the same molecule, and an initial concentration of $200 \mathrm{mgL}^{-1}$.

According to literature data, the molecular structure of clofibric acid is involved in its recalcitrant nature. Indeed, the significant role of this parameter in the recalcitrance of xenobiotic compounds is well known (Evangelista et al. 2010). It is acknowledged that, chlorinated substitutions or structural characteristics such as ring substitutions but also the nature of aliphatic side chain of compounds influence their persistence in the environment, affecting their susceptibility to biological degradation. The target molecule considered in this study contains a chlorophenolic group, but its resistance to biodegradation is in fact due to the steric hindrance from a single extra methyl group (Evangelista et al. 2010).

Results obtained in this work demonstrate, that the both acclimation protocols investigated here had the ability to acclimate Pseudomonas aeruginosa RZS9 biomass to degrade CLA but the biomass obtained from the Protocol 
II had higher pollutant elimination efficiency. For this reason, further optimization experiments were designed with acclimated biomass obtained under this acclimation strategy.

\subsection{Bioremediation of CLA by acclimated biomass: effect of the initial concentration of carbon co- substrate}

As stated above, in many cases the xenobiotic molecule cannot serves as the sole carbon and energy sources to maintain biomass and induce expression of relevant enzymes and/or cofactors for the assimilation by microorganisms. Many works suggested that the main biodegradation pathway of such compounds is probably attributed to a microbial cometabolic activity based on the use of a growth substrate or to another utilizable compound. It requires the obligatory presence of a growth substrate which helps and maintains the biomass growth and produces the relevant enzymes/cofactors involved in the cometabolic biodegradation of the pollutant (Tran et al. 2013). Moreover, it should be noted the degradation efficiency of a pollutant as well as the formation of by-products is influenced by the different growth substrates added. The degradation of organic pollutants refractory to biological decomposition was frequently observed or enhanced in the presence of easily assimilated carbon substrates (Gren et al. 2010). For all these reasons the biodegradation of CLA by acclimated biomass was also investigated under cometabolic conditions. For comparison purposes glucose was used as a simple source of carbon. Tests were carried out for different initial glucose concentrations in order determine the optimum conditions allowing an efficient removal of the target molecule.

The experiments were performed in batch reactors, using as inoculum, biomass that was previously acclimated to CLA following the Protocol II (cells in the decline phase) with $1 \mathrm{mgL}^{-1} \mathrm{CLA}$ and1.25 $\mathrm{mg} \mathrm{L}^{-1}$ glucose. Different initial glucose concentrations ranging from 0.25 to $10 \mathrm{gL}^{-1}$ were tested. Fig 6a shows the CLA removal efficiencies determined after $72 \mathrm{~h}$ of incubation. It can be observed that the CLA degradation activity was modified by the addition of glucose as carbon co-substrate. For the investigated conditions an optimal value of 2 $\mathrm{gL}^{-1}$ was found for the glucose concentration (Fig.6a). Indeed, the CLA removal yield increased from 19 to 35\% with a rise of the glucose concentration from 0 to $2 \mathrm{gL}^{-1}$. Similarly, Popa et al. (2014) and Popa Ungureanu et al. (2016) showed that the addition of glucose improved the carbamazepine and CLA degradation by Streptomyces spp. Liu et al. (Liu et al. 2013) also demonstrated that the addition of different utilizable carbon substrates (such as sucrose and succinate) enhance the elimination of an insecticide (imidacloprid) by the bacterial strain Stenotrophomonas maltophilia. Moreover, obtained results suggest once again, that the addition of readily available carbon and energy sources facilitate the cells growth (Fig. 6b), but also can act as an inducing agent for the production of relevant enzymes and provide cofactors (i.e. NADPH or NADH) needed for the degradation of the target pollutant.

Beyond a glucose concentration of $2 \mathrm{gL}^{-1}$, the biodegradation yield decreased and was only $22 \%$, which was nearly to the value obtained for the control test (without glucose) carried out with acclimated biomass (19\%) after $72 \mathrm{~h}$ of incubation time (Fig 6a). This result also confirms the positive effect of the bacterial strain acclimation and demonstrates that acclimated Pseudomonas aeruginosa RZS9 strain is able to grow in the presence of the pollutant as the sole carbon and energy source. It can also be noted the decrease of the $\mathrm{pH}$ of the culture medium from 7.3 to 4.5 (Fig.6b). This effect will be attributed to a catabolite repression by glucose, which has been reported by some researchers (Loh and Wang 1997; Satsangee and Ghosh 1990). 
Their findings suggest that the presence of high glucose concentrations can inhibit the use of the target substrate. Moreover, Wang and Loh (1999) and Fakhruddin and Quilty (2005) reported that high concentrations of glucose caused significant drop in $\mathrm{pH}$ and the inhibition of the assimilation of other substrates present in the culture medium.

Fig.6 (a), (b)

\section{Conclusions}

516 This is the first study on the degradation of clofibric acid by Pseudomonas aeruginosa RZS9,a phenol resistant strain isolated from the activated sludge in a sewage treatment plant from Algeria. This work demonstrates that the cometabolic conditions influence the removal efficiency of the CLA with a simultaneous increase of biomass growth. However, under these conditions the strain exhibits a low biodegradation yield; the reached maximum elimination yield was only of $20 \%$ after $72 \mathrm{~h}$ of incubation. Information concerning the acclimation process of the isolated strain to CLA is also given; the acclimation strategy has a significant impact on the removal of the target molecule. Indeed, the acclimation protocol based on the use of cells harvested during the decline phase produced biomass with higher activity. Optimal CLA removal (up to 35\%) was obtained with acclimated biomass in the presence of $2 \mathrm{gL}^{-1}$ of glucose. In addition, the presence of high glucose concentrations negatively impacted the consumption of CLA by the acclimated biomass. In conclusion, the results obtained demonstrated the ability of the selected strain for the removal of the target molecule. To complete this work, research is ongoing dealing with the identification of the degradation metabolites and their toxicity. Moreover, further research is needed to optimize the growth culture conditions of the acclimated strain in order to increase its degradation efficiency. 


\section{References}

Awasthi, S.K., Ashfaq, M., \& Singh, S. (2009) Effect of glucose and chloramphenicol on ABS biodegradation by a bacterial consortium. Biology and Medicine, 1, 15-19.

Cardoso, O., Porcher, J.M., \& Sanchez, W. (2014) Factory-discharged pharmaceuticals could be a relevant source of aquatic environment contamination: Review of evidence and need for knowledge. Chemosphere, 115, 20-30.

Chen, S.H., \& Aitken, M.D. (1999) Salycilate stimulates the degradation of high-molecular weight polycyclic aromatic hydrocarbons by Pseudomonas saccharophyla P15. Environ Science and Technology, 33, 435-439.

Chong, N.M., \& Lin, T.Y. (2007) Measurement of the degradation capacity of activated sludge for a xenobiotic organic. Bioresource Technology, 98, 1124-1127.

Chong, N.M., Huang, W.S., \& Chen, Y.S. (2008) Loss of degradation capacity of activated sludge for a xenobiotic after a period without its influent. Bioresource Technology, 99, 8729-8734.

Chong, N.M. (2009) Modeling the acclimation of activated sludge to a xenobiotic. Bioresource Technology, 100, 5750-5756.

Cruz-Morató, C., Jelic, A., Perez, S., Petrovic, M., Barceló, D., Marco-Urrea, E., Sarrà, M., \& Vicent, T. (2013) Continuous treatment of clofibric acid by Trametes versicolorin a fluidized bed bioreactor: Identification of transformation products and toxicity assessment. Biochemical Engineering Journal, 75, 79-85.

Doll, T.E., \& Frimmel, F.H. (2003) Fate of pharmaceuticals photodegradation by simulated solar UV-light. Chemosphere, 52, 1757-1769.

Domaradzka, D., Guzik, U., Hupert-Kocurek, K., \& Wojcieszyńska, D. (2015) Cometabolic degradation of naproxen by Planococcus sp. Strain S5. Water, Air, \& Soil Pollution, 226, 1-8.

Evangelista, S., Cooper, D.G., \& Yargeau, V. (2010) The effect of structure and a secondary carbon source on the microbial degradation of chlorophenoxy acids. Chemosphere, 79, 1084-1088.

Fakhruddin, A.N.M., \& Quilty, B. (2005) The influence of glucose and fructose on the degradation of 2chlorophenol by Pseudomonas putida CP1. World Journal of Microbiology and Biotechnology, 21, 1541-1548. Favier, L., Simion, A.I., Rusu, L., Pacala, M.L., Grigoras, C., \& Bouzaza, A. (2015) Removal of an organic refractory compound by photocatalysis in batch reactor - a kinetic study. Environmental Engineering and Management Journal, 14, 1327-1338.

Fent, K., Weston, A.A., \& Caminada, D. (2006) Ecotoxicology of human pharmaceuticals. Aquatic Toxicology, 76, 122-159.

Ferro Orozco, A.M., Lobo, C.C., Contreras, E.M., \& Zaritzky, N.E. (2013) Biodegradation of bisphenol-A (BPA) in activated sludge batch reactors: Analysis of the acclimation process. International Biodeterioration and Biodegradation, 85, 392-399.

Fischer, J., Kappelmeyer, U., Kastner, M., Schauer, F., \& Heipieper, H.J. (2010) The degradation of bisphenol A by the newly isolated bacterium Cupriavidus basilensis JF1 can be enhanced by biostimulation with phenol. International Biodeterioration and Biodegradation 64, 324-330.

Gauthier, H., \& Yargeau, V., \& Cooper D.G. (2010) Biodegradation of pharmaceuticals by Rhodococcus rhodochrous and Aspergillus niger by co-metabolism. Science of the Total Environment, 408, 1701-1706.

Godon, J.J., Zumstein, E., Dabert, P., Habouzit, F., \& Moletta, R., Microbial 16S rDNA diversity in an anaerobic digester. Water Science and Technology, 36, 49-55(1997). 
Gren, A.E., Wojcieszynska, D., Guzik, U., Perkosz, M., \& Hupert-Kocurek, K. (2010) Enhanced biotransformation of mononitrophenols by Stenotrophomonas maltophilia KB2 in the presence of aromatic compounds of plant origin. World Journal of Microbiology and Biotechnology, 26, 290-295.

Grenni, P., Patrolecco, L., Ademollo, N., Tolomei, A., \& Barra Caracciolo, A. (2013) Degradation of gemfibrozil and naproxen in a river water ecosystem. Microchemical Journal, 107, 158-164.

Holt, J., Krieg, N., Sneath, P., Staley, J., \& Williams, S. (1994) Bergey’s manual of determinative bacteriology, ninth ed. Williams \&Wilkins. Baltimore.

Huang, Z., Wang, P., Li, H., Lin, K., Lu, Z., Guo, X., \& Liu, Y. (2014) Community analysis and metabolic pathway of halophilic bacteria for phenol degradation in saline environment. International Biodeterioration and Biodegradation, 94, 115-120.

Jones, O.A.H., Voulvoulis, N., \& Lester, J.N. (2007) The occurrence and removal of selected pharmaceutical compounds in a sewage treatment works utilizing activated sludge treatment. Environmental Pollution, 145, 738744.

Juhasz, A.L., \& Naidu, R. (2000) Bioremediation of high molecular weight polycyclic aromatic hydrocarbons: a review of the microbial degradation of benzo[a]pyrene. International Biodeterioration and Biodegradation, 45, 57-88.

Khetan, S.K., \& Collins, T.J. (2007) Human Pharmaceuticals in the Aquatic Environment: A Challenge to Green Chemistry. Chemical Reviews, 107, 2319-2364.

Kosjek, T., Heath, E., Pérez, S., Petrović, M., \& Barceló, D. (2009) Metabolism studies of diclofenac and clofibric acid in activated sludge bioreactors using liquid chromatography withupole - time-of-flight mass spectrometry. Journal of Hydrology, 372, 109-117.

Larcher, S., \& Yargeau, V. (2011) Biodegradation of sulfamethoxazole by individual and mixed bacteria. Applied Microbiology and Biotechnology, 91, 211-218.

Liu, Z., Dai, Y., Huan, Y., Liu, Z., Sun, L., Zhou, Q., Zhang, W., Sang, Q., Wei, H., \& Yuan, S. (2013) Different utilizable substrates have different effects on cometabolic fate of imidachloprid in Stenotrophomonas maltophila. Applied Microbiology and Biotechnology, 97, 6537-6547.

Loh, K.C., \& Wang, S.J. (1997) Enhancement of biodegradation of phenol and a nongrowth substrate 4chlorophenol by medium augmentation with conventional carbon sources. Biodegradation, 8, 329-338.

Luo, Y., Guo, W., Ngo, H.H., Nghiem, L.D., Hai, F.I., Zhang, J., Liang, S., \& Wang, X.C. (2014) A review on the occurrence of micropollutants in the aquatic environment and their fate and removal during wastewater treatment. Science of the Total Environment, 473-474, 619-641.

Mangat, S.S., \& Elefsiniotis, P. (1999) Biodegradation of the herbicide 2,4-dichlorophenoxyacetic acid (2,4-D) in sequencing batch reactors. Water Research, 33, 861-867.

Murcia, M.D., Gómez, M., Gómez, E., Gómez, J.L., Sinada, F.A., \& Christofi, N. (2012) Testing a Pseudomonas putida strain for 4-chlorophenol degradation in the presence of glucose. Desalination and Water Treatment, 40, 33-37.

Nakada, N., Shinohara, H., Murata, A., Kiri, K., Managaki, S., Sato, N., \& Takada, H. (2007) Removal of selected pharmaceuticals and personal care products (PPCPs) and endocrine-disrupting chemicals (EDCs) during sand filtration and ozonation at a municipal sewage treatment plant. Water Research, 41, 4373-4382. 

Degradation of terbuthylazine, difeconazole and pendimethalin pesticides by selected fungi cultures. Science of the Total Environment, 435-436, 402-410.

Popa, C., Favier, L., Dinica, R., Semrany, S., Djelal, H., Amrane, A., \& Bahrim, G. (2014) Potential of newly wild Streptomyces stains as agents for the biodegradation of a recalcitrant pharmaceutical, carbamazepine. Environmental Technology, 35, 3082-3091. Popa Ungureanu, C., Favier, L., Bahrim, G., \& Amrane, A. (2015) Response surface optimization of experimental conditions for carbamazepine biodegradation by Streptomyces MIUG 4.89. New Biotechnology, 32, 347-357.

Popa Ungureanu, C., Favier, L., \& Bahrim, G. (2016) Screening of soil bacteria as potential agents for drugs biodegradation: a case study with clofibric acid: Soil bacteria as potential agents for drugs biodegradation. Journal of Chemical Technology and Biotechnology, 91, 1646-1653. Quintana, J., Weiss, S., \& Reemtsma, T. (2005) Pathways and metabolites of microbial degradation of selected acidic pharmaceutical and their occurrence in municipal wastewater treated by a membrane bioreactor. Water Research, 39, 2654-2664. Sacher, F., Lange, F.T., Brauch, H.J., \& Blankenhorn, I. (2001) Pharmaceuticals in ground waters: analytical methods and results of a monitoring program in Baden-Württemberg, Germany. Journal of Chromatography A, 938, 199-210.

Sahinkaya, E., \& Dilek, F.B. (2005) Biodegradation of 4-chlorophenol by aclimated and unacclimated activated sludge - Evaluation of biokinetic coefficients. Environmental Research, 99, 243-252. Sahinkaya, E., \& Dilek, F.B. (2007) Biodegradation kinetics of 2,4-dichlorophenol by acclimated mixed cultures. Journal of Biotechnology, 127, 716-726. Salgado, R., Noronha, J.P., Oehmen, A., Carvalho, G., \& Reis, M.A.M. (2010) Analysis of 65 pharmaceuticals and personal care products in 5 wastewater treatment plants in Portugal using a simplified analytical methodology.Water Science and Technology 62, 2862-2871. Salgado, R., Oehmen, A., Carvalho, G., Noronha, J.P., \& Reis, M.A.M. (2012) Biodegradation of clofibric acid and identification of its metabolites. Journal of Hazardous Materials, 241-242, 182-189. Satsangee, R., \& Ghosh, P. (1990) Anaerobic degradation of phenol using an acclimated mixed culture. Applied Microbiology and Biotechnology, 34, 127-130.

640 Semrany, S., Favier, L., Djelal, H., Taha, S., \& Amrane, A. (2012) Bioaugmentation: possible solution in the treatment of Bio-refractory organic compounds (Bio-ROCs). Biochemical Engineering Journal, 69, 75-86.

642 Tauxe-Wuersch, A., De Alencastro, L.F., Grandjean, D., \& Arradellas, J.T. (2005) Occurrence of several acidic 643 drugs in sewage treatment plants in Switzerland and risk assessment. Water Research, 39, 1761-1772.

644 Tran, N.H., Urase, T., \& Kusakabe, O. (2009) The characteristics of enriched nitrifier culture in the degradation 645 of selected pharmaceutically active compounds. Journal of Hazardous Materials, 171, 1051-1057.

646 Tran, N.H., Urase, T., Ngo, H.H., Hu, J., \& Ong, S.L. (2013) Insight into metabolic and cometabolic activities of 647 autotrophic and heterotrophic microorganisms in the biodegradation of emerging trace organic contaminants. 648 Bioresource Technology, 146, 721-731.

649 Wang, S.J., \& Loh, K.C. (1999) Facilitation of cometabolic degradation of 4-chlorophenol using glucose as an 650 added growth substrate. Biodegradation, 10, 261-269. 
Weisburg, W.G., Barns, S.M., Pelletier, D.A., \& Lane, D.J. (1991) 16S ribosomal DNA amplification for phylogenetic study. Journal of Bacteriology, 173, 697-703. Winkler, M., Lawrence, J.R., \& Neu, T. (2001) Selective degradation of ibuprofen and clofibric acid in two model river biofilm systems. Water Research, 35, 3197-3205. Yamanaka, H., Moriyoshi, K., Ohmoto, T., Ohe, T., \& Sakai, K. (2007) Degradation of Bisphenol A by Bacillus pumilus isolated from kimchi, a traditionally fermented food. Applied Biochemistry and Biotechnology, 136, 3951.

658 Ye, F.X., \& Shen, D.S. (2004) Acclimation of anaerobic sludge degrading chlorophenols and the biodegradation 659 kinetics during acclimation period. Chemosphere, 54, 1573-1580.

660 Zhang, C., Zeng, G., Yuan, L., Yu, J., Li, Huang, G., \& Liu, B.X.iH. (2007) Aerobic degradation of bisphenol A 661 by Achromobacter xylosoxidans strain B-16 isolated from compost leachate of municipal solid waste. 662 Chemosphere, 68, 181-190.

663 Zuccato, E., Castiglioni, S., Bagnati, R., Melis, M., \& Fanelli, R. (2010) Source, occurrence and fate of 664 antibiotics in the Italian aquatic environment. Journal of Hazardous Materials, 179, 1042-1048.

665 Zwiener, C., \& Frimmel, F. (2003) Short-term tests with a pilot sewage plant and biofilm reactors for the 666 biological degradation of the pharmaceutical compounds clofibric acid, ibuprofen, and diclofenac. Science of the 667 Total Environment, 309, 201-21.

668

669

670

671

672 
Table 1 Physicochemical properties of clofibric acid (CLA).

\begin{tabular}{|l|l|}
\hline & \\
\hline Chemical Structure & $\underline{882-09-7}$ \\
\hline Formula & $\mathrm{C}_{10} \mathrm{H}_{11} \mathrm{ClO}_{3}$ \\
\hline Therapeutic class & lipidregulator \\
\hline Appearance & white solid \\
\hline Molecular weight & $214.65 \mathrm{~g} \mathrm{~mol}^{-1}$ \\
\hline Water solubility & $573 \mathrm{mg} \mathrm{l}^{-1}\left(25^{\circ} \mathrm{C}\right)^{\mathbf{b}}$ \\
\hline pK & $3^{\mathbf{a}}$ \\
\hline Log $\mathrm{k}_{\text {ow }}$ & $2.57^{\mathbf{a}}$ \\
\hline Log $\mathrm{D}_{\text {ow }}$ & $-0.42^{\mathbf{a}}$ \\
\hline Henry’slaw constant & $2.1910^{-8} \mathrm{~Pa} \mathrm{~m}^{3} \mathrm{~mol}^{-1}\left(25^{\circ} \mathrm{C}\right)^{\mathbf{b}}$ \\
\hline
\end{tabular}

${ }^{\mathrm{a}}$ Zhang et al. 2012.

${ }^{\mathrm{b}}$ Zhang et al. 2014. 
Table 2 Morphological and biochemical characteristics of isolated strain.

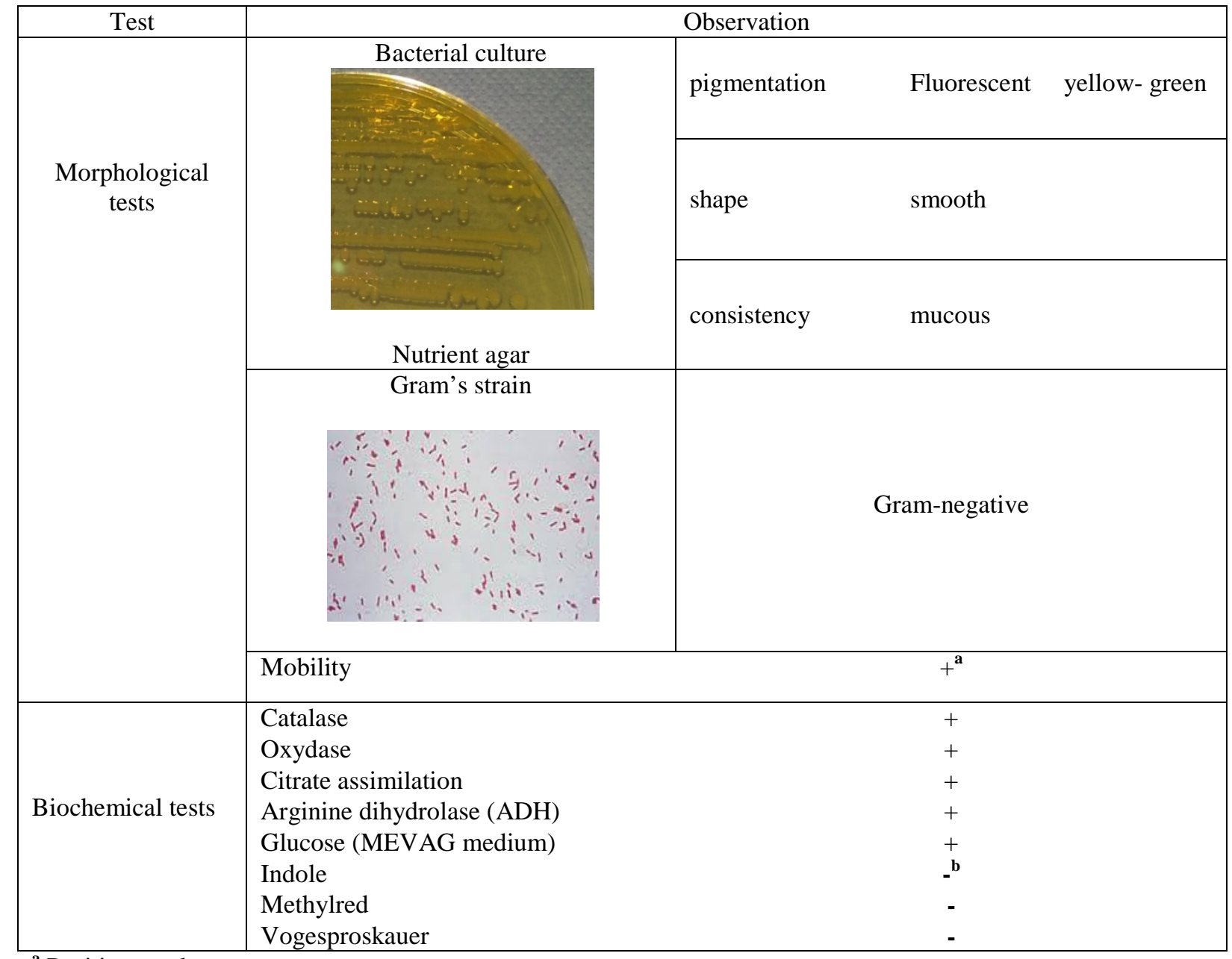

\footnotetext{
${ }^{a}$ Positive result.

b Negative result.
} 
Figure captions

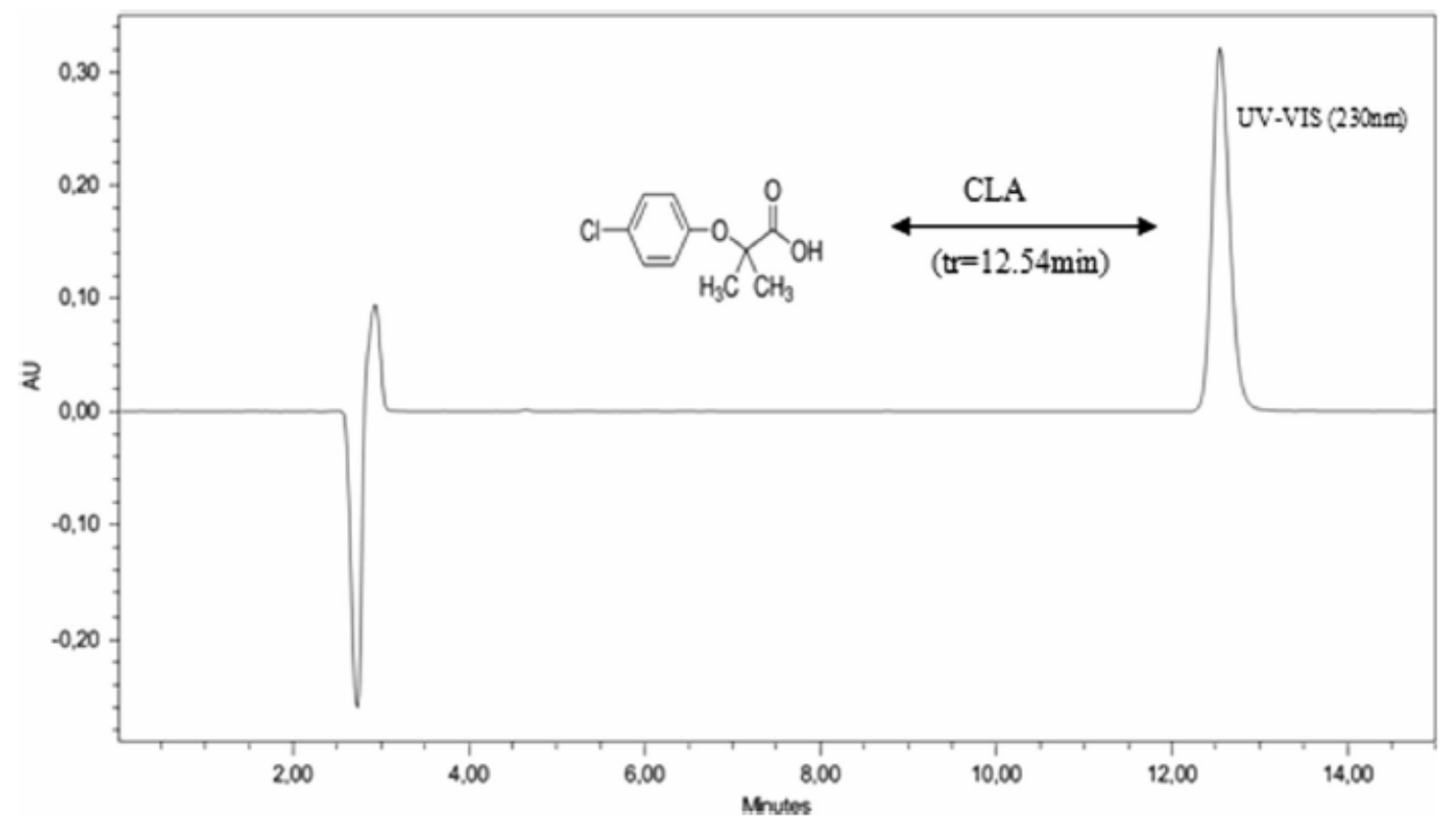

Fig. 1 Chromatogram obtained by HPLC-UV analysis for standard solution of CLA. 


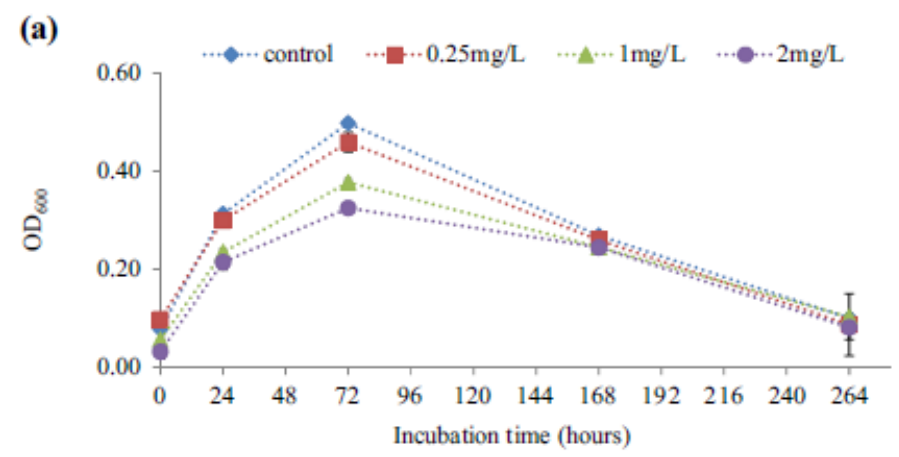

(b)

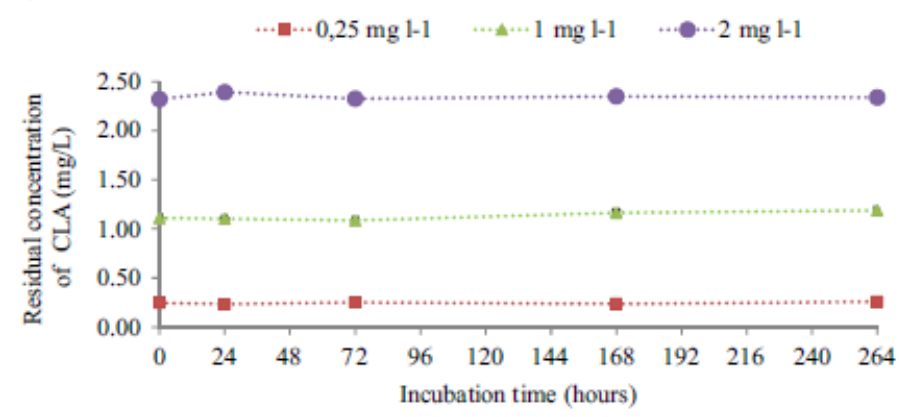

(c)

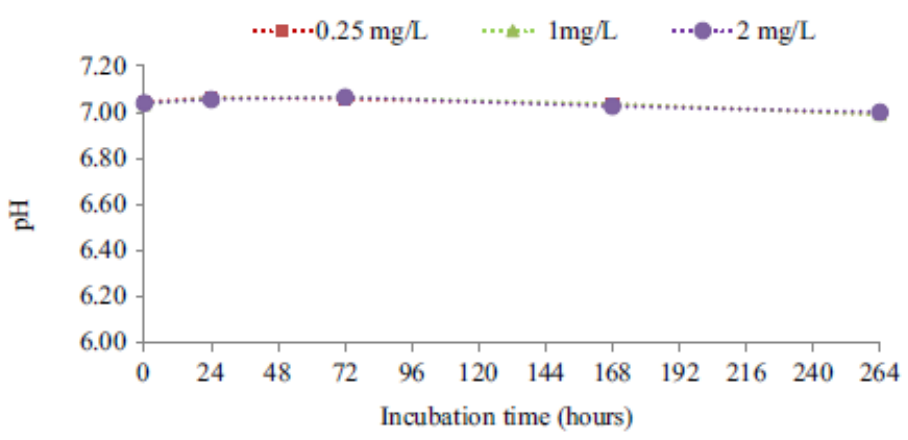

Fig. 2 Profiles of cells growth, $\mathrm{pH}$ and residual concentration of CLA for the biodegradation experiments without co-substrate and non-adapted cells conducted at different initial pollutant concentrations; $37^{\circ} \mathrm{C}, 150 \mathrm{rpm}$ and an initial $\mathrm{pH}=7 \pm 0.1$. (a)Pseudomonas aeruginosa RZS9 growth curves (expressed as optical density at 600 $\mathrm{nm}$ ); (b) residual concentration of CLA; (c) $\mathrm{pH}$ profiles. 

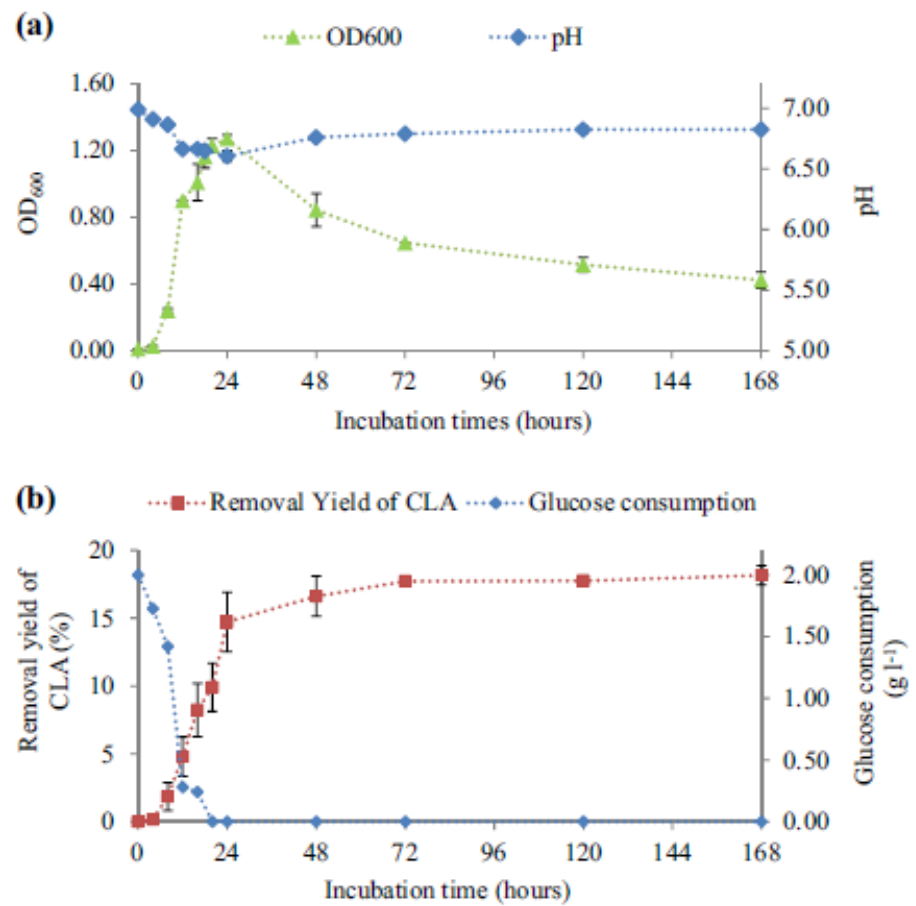

Fig. 3 Time-course variation in $\mathrm{OD}_{600}$ values, $\mathrm{pH}$, CLA removal yield and glucose consumption for the biodegradation test carried out with glucose as carbon co-substrate and non-adapted cells. (a) cell growth and $\mathrm{pH}$ profiles; (b) removal yield of CLA and glucose consumption; [CLA $]_{0}=1 \mathrm{mg} \mathrm{L}^{-1}$; [glucose $]_{0}=2 \mathrm{~g} \mathrm{~L}^{-1}$; $37^{\circ} \mathrm{C}$;

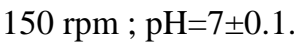

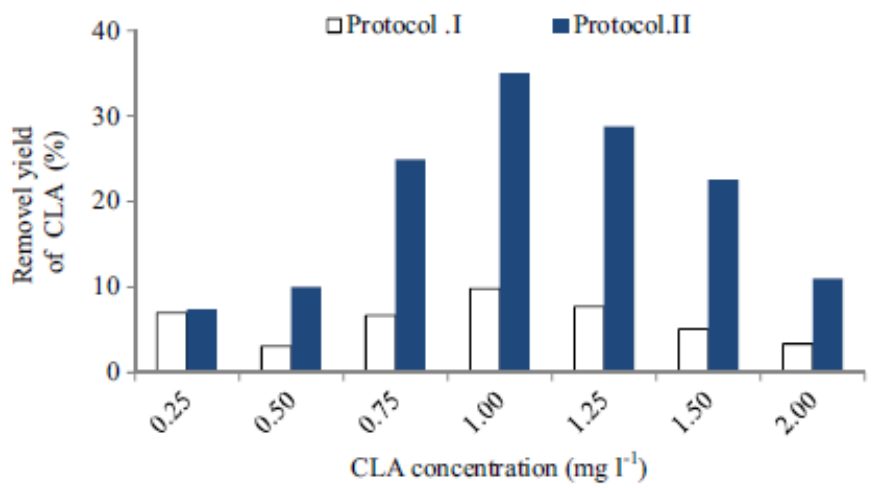

Fig. 4 Removal yields of CLA at the end of exponential phase (24h) as a function of initial CLA concentration during the consecutive batch assays performed for the both acclimation procedures. [glucose $]_{0}=2,1.75,1.5$, $1.25,1,0.5,0.25 \mathrm{~g} \mathrm{~L}^{-1}$; $37^{\circ} \mathrm{C}$; $150 \mathrm{rpm} ; \mathrm{pH}=7 \pm 0.1$. 

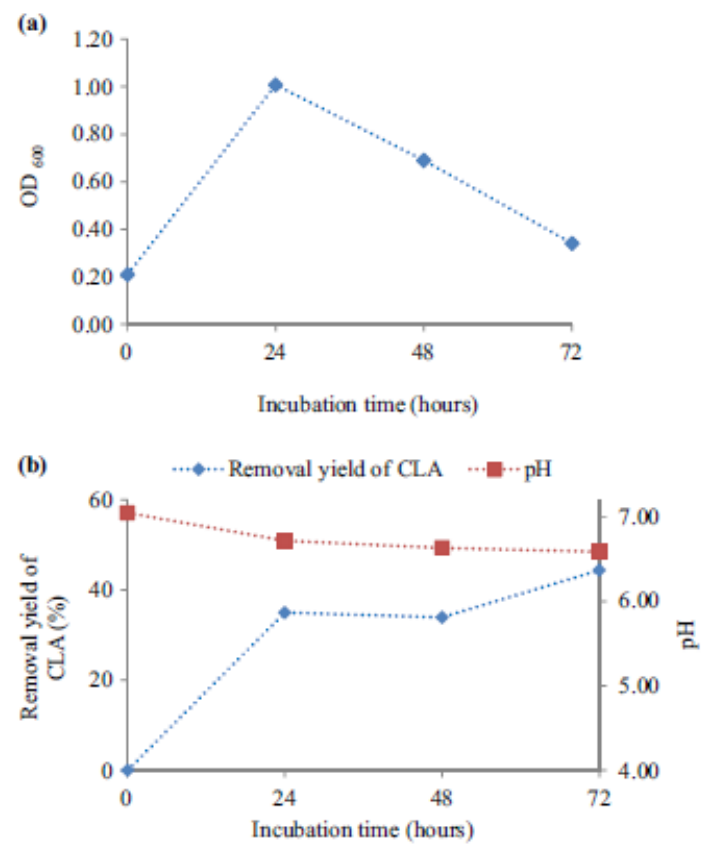

Fig. 5 Time course of the acclimation experiments during the batch assay performed at $[\mathrm{CLA}]_{0}=1 \mathrm{mg} \mathrm{L}^{-1}$; [glucose $]_{0}=1.25 \mathrm{~g} \mathrm{~L}^{-1} ; 37^{\circ} \mathrm{C} ; 150 \mathrm{rpm} ; \mathrm{pH}=7 \pm 0.1$ for cells acclimation to CLA following the protocol II. (a) growth of Pseudomonas aeruginosa RZS9 strain; (b) removal yield of CLA and pH profiles.
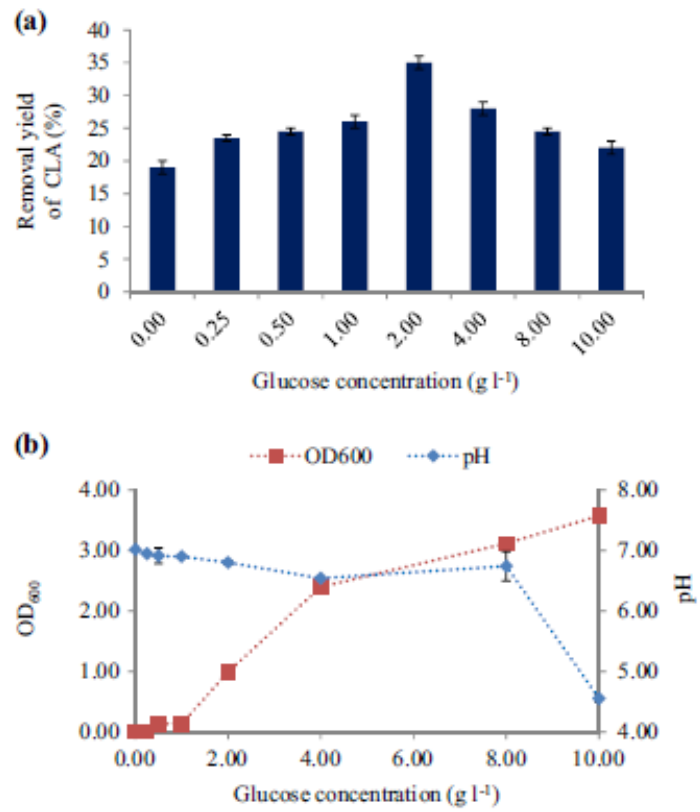

Fig. 6 Effect of different initial glucose concentrations, after 72h of incubation time. (a) removal yield of CLA; (b) cell growth and $\mathrm{pH}$ profiles.[CLA $]_{0}=1 \mathrm{mg} \mathrm{L}^{-1}$; [glucose $]_{0}$, ranging from 0 to $10 \mathrm{~g} \mathrm{~L}^{-1} ; 37^{\circ} \mathrm{C} ; 150 \mathrm{rpm} ; \mathrm{pH}=7$ \pm 0.1 . 